\title{
An Inventory Replenishment Model under Purchase Dependency in Retail Sale
}

\author{
Pradip Kumar Bala \\ Discipline of Management \\ Studies \\ IIT, Roorkee, India
}

\begin{abstract}
In multi-item inventory with very large number of items in retail sale stores, purchase dependency in demand amongst the items can be described by association rules mined from sale transaction data. With the knowledge of association rules, inventory replenishment policy can be designed which will result in low inventory cost and better profitability. The relevant inventory costs include the cost of lost sale along with other conventional inventory costs. Various inventory replenishment policies can be simulated on synthetic data for a particular purchase pattern. Using sequence of random numbers, future demand data can be generated to depict purchase dependency in demand given by an association rule observed in the past sale transaction data. To learn the cost effectiveness of different inventory replenishment policies, simulation is conducted on the generated future demand data. Based on cost-benefit analysis of all the applicable inventory replenishment policies, the best one can be selected for implementation.
\end{abstract}

\section{General Terms}

Data Mining, Association Rule, Inventory, Retail

\section{Keywords}

Data Mining, Association rule, Purchase Dependency, Retail sale, Multi-item inventory

\section{INTRODUCTION}

In inventory management practices, mostly we come across multi-item inventory with different types of joint replenishment policies [1]. Period of replenishment may be same for all the items [2], or, different, in multiples, for different items as given in [3], [4] and [5]. Purchase dependency in demand of the items is not addressed in these joint replenishment methodologies. The problem of multiitem inventory is more challenging when there is purchase dependency in the demand or usage pattern amongst the items or itemsets (Itemset refers to a set of one or more items). In fact, demand purchase dependency in inventory with very large number of items, where there is a possibility of many interdependencies, has remained unaddressed.

Purchase dependency in the demand amongst the items can be one to one, one to many, many to one or many to many. Sometimes a customer buys an itemset depending on the availability of some other itemset. Customer purchases an itemset only when another itemset is also in stock. Under such conditional purchase pattern, even though an itemset is in stock but the associated itemset is not in stock, the case is like an out-of-stock situation for such customers for the former itemset. To explain the above situation further, say, in a store, item B is in stock and item A is out of stock. A customer is interested in purchasing $\mathrm{B}$, provided $\mathrm{A}$ is also available in the store, so that he can purchase A and B both. As the demand for B depends on demand for A, he will not purchase B, if A is not available. Under this situation, we can say that stock of $\mathrm{B}$ is as good as a stock-out situation for that customer. Hence, if $\mathrm{A}$ is not in stock, there will be no sale of B also in many cases. This example depicts a case of purchase dependency in demand. The retailer loses not only the profit for selling A, but also the profit for selling B. Moreover, holding cost for carrying inventory of B gets added to the total inventory cost. Irrespective of these costs arising out of purchase dependency in demand, general carrying costs of inventory and order placement costs are always there. Lost sale cost and inventory carrying cost present complex trade-off for the profitable operation of the business.

Under the situation as mentioned above, with the additional information of purchase dependency in demand pattern amongst the items, finding an optimal ordering policy in retail sale inventory becomes a complex problem. The complexity of multi-item inventory problem requires a reliable methodology of determining the operating parameters that optimize the inventory control.

Association rules can be used to describe purchase dependency in demand. Association rules are mined from the past sale transaction data. These rules depict the purchase pattern of the customers and it is expected that these rules will be observed in future transactions. This is why these rules can be treated as a useful input for designing inventory replenishment policy. Anticipated sale transaction data describing a particular purchase dependency in demand given by an association rule can be generated for the future. An applicable inventory replenishment policy can be simulated on the generated data. By simulating various inventory replenishment policies on the same generated future demand data, comparison of the performance of different policies can be made with cost-benefit analysis. Based on the performance, the best policy can be suggested for implementation.

A number of applicable inventory replenishment policies have been suggested in our research work and have also been simulated on predicted demand data generated by using random numbers. Cost-benefit analysis suggests the policy to be adopted.

Work in [6] gave two economic order quantity models where multiple items use a common resource. The common resource may be space in an automated warehouse or total capital invested in inventory. Paper [7] developed heuristics and bounds for single resource multi-item inventory system where each of the items in the inventory system has a constant demand or depletion rate, uses a certain amount of limited resource, e.g., storage space and is being replenished instantaneously according to a policy with stationary order 
size and interval. Such policies are called stationary order size and interval (SOSI) policies in [6] .

Research work in [8] gave a multi-item inventory replenishment policy with limited number of items. However, it does not address the correlation in the demand pattern of the items. A continuous review inventory model has been developed in [9] for a multi-item, multi-echelon distribution system in which service level constraint exists for general groups of items across multiple locations and channels. Multiitem inventory systems have been addressed with random and seasonally fluctuating, and correlated demands with time [10]. Inventory modelling has been done for a multi-product continuous review inventory system with stochastic demand, backorders, and a budget constraint in [11] which models a multi-item stochastic inventory system with backordered shortages when estimation of marginal backorder cost is available, and payment is due upon order arrival. The budget constraint is converted into a storage constraint.

Using Markovian model for a two-item inventory system with correlated demands and coordinated replenishments, an expression for the long-run total cost per unit of time under the can-order replenishment policy has been obtained [12].

Mutual increase in the demand of one commodity due to the presence of the other has been accommodated for the first time in the model of [13]. The paper considers the correlation between the demands of two items and gives a new approach towards a two-item inventory model for deteriorating items with a linear stock-dependent demand rate. A linear demand rate has been assumed in the work, that is, more is the inventory, more is the demand.

Association rule is a type of data mining technique that correlates one set of items or events with another set of items or events. Questions such as "if a customer purchases product A, how likely is he to purchase product B?" and "What products will a customer buy if he buys products C and D?" are answered by association rules. Association Rules will allow us to find rules of the kind, "If X then (likely) Y", where $\mathrm{X}$ and $\mathrm{Y}$ can be single values, items, words, etc., or conjunctions of values, items, words, etc. (e.g., if $(\mathrm{Car}=$ Santro and Gender $=$ Male and Age $<25)$ then $($ Risk = High and Insurance $=$ High)). Association rule mining algorithm employs association or linkage analysis, searching transactions from operational systems for interesting patterns with a high probability of repetition. Association rules are mined from past sale transaction data with large number of transactions. Sale transaction implies purchase of at least one item. Hence, a sale transaction (or, transaction) contains the list of items purchased by a customer in an instance.

As per the definition of association rule, a rule, $\mathrm{X}=>\mathrm{Y}$, can be used to describe the purchase dependency of demand, where, $\mathrm{X}$ and $\mathrm{Y}$ are two itemsets. " $\mathrm{X}=>\mathrm{Y}$ " is read as " $\mathrm{X}$ associates $Y$ " and it says that purchase of $X$ implies purchase of $Y$ with some measures of strength. Now, we will discuss on the strength of an association rule. Strength of an association rule can be defined in the framework of 'support', 'confidence' and 'lift'.

For a given transaction database, if ' $\mathrm{X}$ ' and ' $\mathrm{Y}$ ' are two items/itemsets such that $\mathrm{X} \cap \mathrm{Y}=\Phi, \quad$ i.e., there is no common item in them, the rule $\mathrm{X}=>\mathrm{Y}$ is a valid association rule if it satisfies the minimum threshold values for support, confidence, and lift which are defined as below.
Support: A transaction, $\mathrm{t}$, is said to support an itemset, I, if I is present in t. 'Support' of an itemset in a transaction database is defined as the percetntage support of the itemset. If the database supports $\{\mathrm{X}, \mathrm{Y}\}$ by $\mathrm{s} \%, \mathrm{X}=>\mathrm{Y}$ holds with support $\mathrm{s} \%$.

Confidence: $\mathrm{X}=>\mathrm{Y}$ holds with confidence $\mathrm{c} \%$, if $\mathrm{c} \%$ of the transaction in the database that supports ' $\mathrm{X}$ ' also supports ' $\mathrm{Y}$ '.

Lift (or lift ratio): Lift of $X=>Y$ is the lift given by $X$ to $Y$ while a customer purchases $\mathrm{Y}$. A lift ratio greater than 1.0 suggests that there is some usefulness to the rule. The larger the lift ratio, the greater is the strength of the association.

Lift $=($ Percentage Confidence $) /($ Percentage Support of Y $)$

Use of data mining algorithm in [14] helps in mining frequent itemsets efficiently from sale transaction data from which the association rules are obtained. Sale transaction data is generally represented in binary form of the 'presence' or 'absence' of the items in a transaction. 'Presence' is usually denoted by ' 1 ' and 'absence' is usually denoted by ' 0 ' in binary representation of the sale transactions. In a transaction, at least one item must be 'present, otherwise, it will not be called a transaction. With given threshold values of support, confidence and lift, all possible association rules can be mined.

Association rules are used as input to many decision-making processes. In [15], a method to select inventory items from the association rules has been proposed for cross-selling consideration. This gives methodology to choose a subset of items which can give the maximal profit with the consideration of cross-selling effect. However, this does not give any policy on inventory replenishment.

For retail sale multi-item inventory with very large number of items and interdependencies in demand of the items, the problem of inventory replenishment has remained unaddressed. Association rules can be used to describe purchase dependency in demand in 'IF-THEN' form. Historical sale transaction data can be used to find the purchase dependencies in the form of association rules $[16$, $17,18]$. If the association rules are true representative of customers' purchase behaviour over a period of time, it is expected that these rules will be observed in future demand pattern of the customers as well. Based on this representation of association rules, our research makes an effort to develop a methodology to analyze various applicable inventory replenishment policies in the context of purchase dependency in demand of the items.

\section{MODEL DEVELOPMENT}

For any kind of decision making process, more we know about the system, better we decide. Association rules can be used as additional knowledge for the purpose of inventory replenishment. Association rules depict if-then kind of purchase dependency in demand of the items and knowledge of these rules can find application in replenishment of inventory.

If purchase dependency in demand between two items $\mathrm{A}$ and $\mathrm{B}$ is given by the association rule, $\mathrm{A} \Rightarrow \mathrm{B}$, there may arise four types of situations while replenishing inventory for A and B. At some point of time, it may be that both $\mathrm{A}$ and $\mathrm{B}$ are in stock, whereas at some other point of time, both A and B are not in stock. There may also be situations when only one of the two items will be in stock - that is, either A or B is present. Our present research addresses the situation when A 
is not in stock, but B is in stock. Under such situations, although B is in stock, some of the customers who come to purchase both A and B will not purchase B as A is not in stock and there is an purchase dependency in the demand of two items such that demand of B depends on purchase of A. Hence, there will be lost sale for A and B both. In other words, although B is in stock, it is as good as out of stock situation for the item. In such cases, if $\mathrm{A}$ and $\mathrm{B}$ are replenished individually, without any coordination between two, it will be more likely to come across the situations where A is not in stock but B is in stock. This calls for a coordinated replenishment policy for $\mathrm{A}$ and $\mathrm{B}$.

Synthetic data can be generated for future demand data so that it represents the same purchase dependency/interdependencies (in the form of association rule/rules with the items for which inventory replenishment policy is to be designed) as observed in the actual past transaction data. Two joint replenishment policies have been proposed in the present research for addressing interdependencies in demand. These two replenishment policies have been simulated using synthetic data. Based on available literature, for another joint replenishment policy (in addition to two proposed joint replenishment policies) and two individual replenishment policies also, simulation has been done. So, in total, five replenishment policies have been simulated on same set of generated future demand data. Based on cost-benefit analysis, performance of the policies is compared and the best one can be chosen for implementation.

The steps in the model can be summarized as given below.

1. Mine the association rules from the past sale transaction data.

2. Select an association rule for implementation.

3. Generate future demand data (for the item/items finding place in the selected association rule) so that data mining from the generated data set yields the selected association rule with same support, confidence and lift.

4. Based on the past sale transaction data and other required information, design the operating parameters for various inventory replenishment policies.

5. Simulate the inventory replenishment policies obtained in step-4, one by one, on the generated future demand data.

6. Compare the performance of the simulations in step- 5 based on cost-benefit analysis.

7. Select the best inventory replenishment policy obtained in step-5 for implementation.

A. Working with various replenishment policies in multi-item inventory with interdependent demand

For an association rule, $x=>y$, to capture the knowledge of the rule while replenishing inventory of these items, some of the applicable inventory replenishment policies have been discussed as given below.

Assumptions:

(All the costs have been expressed in Indian currency, 'Rs.')

Cost (in Rs.) per unit of $\mathrm{x}=\mathrm{C}_{\mathrm{x}}$

Cost (in Rs.) per unit of $y=C_{y}$
Factor for cost of holding Rs. 1 for a year $=\mathrm{I}$ [Hence, cost of holding (in Rs.) per unit per year for $\mathrm{x}=\mathrm{IC}_{\mathrm{x}}$ and similarly, cost of holding (in Rs.) per unit per year for $\left.\mathrm{y}=\mathrm{IC}_{\mathrm{y}}\right]$

Order placement cost (in Rs.) per order $=\mathrm{S}$

Profit earned (in Rs.) per unit of $x=P_{x}$

Profit earned (in Rs.) per unit of $\mathrm{y}=\mathrm{P}_{\mathrm{y}}$

Annual demand for $\mathrm{x}=\mathrm{D}_{\mathrm{x}}$

Annual demand for $\mathrm{y}=\mathrm{D}_{\mathrm{y}}$

Daily average demand for $\mathrm{x}=\mathrm{d}_{\mathrm{x}}=\mathrm{D}_{\mathrm{x}} / 365$ (assuming 365 days operating in a year)

Daily average demand for $\mathrm{y}=\mathrm{d}_{\mathrm{y}}=\mathrm{D}_{\mathrm{y}} / 365$ (assuming 365 days operating in a year)

Standard deviation of daily demand for $\mathrm{x}=\mathrm{s}_{\mathrm{x}}$

Standard deviation of daily demand for $\mathrm{x}=\mathrm{s}_{\mathrm{y}}$

For all the analyses in the future demand data, the inventoryon-hand in the beginning of the period has been kept at corresponding EOQs of $\mathrm{x}$ and $\mathrm{y}$. Hence, for each policy, it is assumed that one order was already placed before simulating of the policy and its order placement cost has also been accounted for calculating the total cost.

B. Inventory replenishment policies based on individual replenishment of associated items

For independent replenishment, the EOQ formula of classical inventory models is $\mathrm{EOQ}=\sqrt{ }(2 \mathrm{DS} / \mathrm{H})$.

EOQ for $x=Q_{x}=\sqrt{ }\left[\left(2 D_{x} S\right) /\left(I_{x}\right)\right]$

Number of orders per year for $\mathrm{x}=\mathrm{n}_{\mathrm{x}}=\mathrm{D}_{\mathrm{x}} / \mathrm{Q}_{\mathrm{x}}$

Cycle time for $\mathrm{x}$ (in days) $=\mathrm{t}_{\mathrm{x}}=365 / \mathrm{n}_{\mathrm{x}}$ (approximated to the nearest integer value)

Similarly for $\mathrm{y}$,

EOQ for $y=Q_{y}=\sqrt{ }\left[\left(2 D_{y} S\right) /\left(I_{y}\right)\right]$

Number of orders per year for $\mathrm{y}=\mathrm{n}_{\mathrm{y}}=\mathrm{D}_{\mathrm{y}} / \mathrm{Q}_{\mathrm{y}}$

Cycle time for $\mathrm{x}$ (in days) $=\mathrm{t}_{\mathrm{y}}=365 / \mathrm{n}_{\mathrm{y}}$

Based on the above analysis, two applicable inventory replenishment policies are as given below.

Classical Policy-1 (CP-1): Individual replenishment based on cycle time

CP-1 is a periodic review policy (P-Policy). With the knowledge of EOQs and Cycle times for $\mathrm{x}$ and $\mathrm{y}$, individual replenishment is considered without any coordination between two. Lots of $Q_{x}$ units are received for $x$ in every $t_{x}$ number of days and lots of $Q_{y}$ units are received for $y$ in every $t_{y}$ number of days.

Classical Policy-2 (CP-2): Individual replenishment based on lead time and safety stock

CP-2 is denoted by $(\mathrm{R}, \mathrm{Q})$ which is based on ordering the quantity of EOQ (i.e., Q) at re-order point (i.e, R). For individual replenishment, we consider lead time (L) between order placement and order receipt (same lead time for $\mathrm{x}$ and $\mathrm{y}$ 
has been considered) and a common order service level (OSL) for $\mathrm{x}$ and $\mathrm{y}$. Following computations can be made.

Demand during lead time for $\mathrm{x}=\mathrm{Ld}_{\mathrm{x}}$

Standard deviation of demand during lead time for $\mathrm{x}=\mathrm{s}_{\mathrm{x}} \mathrm{L}^{1 / 2}$

Demand during lead time for $\mathrm{y}=\operatorname{Ld}_{\mathrm{y}}$

Standard deviation of demand during lead time for $\mathrm{y}=\mathrm{s}_{\mathrm{y}} \mathrm{L}^{1 / 2}$

Corresponding to the OSL chosen, $\mathrm{z}$-value $\left(\mathrm{z}_{0}\right)$ is obtained from standard normal distribution table, assuming normal distribution of demand in an order cycle.

Safety Stock for $\mathrm{x}=\mathrm{z}_{0}$ (Standard deviation of demand during lead time for $\mathrm{x})=\mathrm{z}_{0}\left(\mathrm{~s}_{\mathrm{x}} \mathrm{L}^{1 / 2}\right)$

ROP for $\mathrm{x}=\mathrm{r}_{\mathrm{x}}=$ Demand during lead time for $\mathrm{x}+$ Safety Stock for $\mathrm{x}=\mathrm{Ld}_{\mathrm{x}}+\mathrm{z}_{0}\left(\mathrm{~s}_{\mathrm{x}} \mathrm{L}^{1 / 2}\right)$

Safety Stock for $\mathrm{y}=\mathrm{z}_{0}$ (Standard deviation of demand during lead time for $\mathrm{y})=\mathrm{z}_{0}\left(\mathrm{~s}_{\mathrm{y}} \mathrm{L}^{1 / 2}\right)$

ROP for $\mathrm{y}=\mathrm{r}_{\mathrm{y}}=$ Demand during lead time for $\mathrm{y}+$ Safety Stock for $\mathrm{y}=\mathrm{Ld}_{\mathrm{y}}+\mathrm{z}_{0}\left(\mathrm{~s}_{\mathrm{y}} \mathrm{L}^{1 / 2}\right)$

In this policy also, orders are placed individually. For $\mathrm{x}$, whenever the inventory reaches its ROP (i.e., $r_{x}$ ) an order of $\mathrm{Q}_{\mathrm{x}}$ units is placed. For $\mathrm{y}$, whenever the inventory reaches its ROP (i.e., $r_{y}$ ), an order of $\mathrm{Q}_{\mathrm{y}}$ units is placed.

C. Inventory replenishment policies based on joint replenishment of associated items

Total annual demand for $\mathrm{x}$ (in Rs.), $\mathrm{T}_{\mathrm{x}}=\mathrm{C}_{\mathrm{x}} \mathrm{D}_{\mathrm{x}}$

Total annual demand for $\mathrm{y}$ (in Rs.), $\mathrm{T}_{\mathrm{y}}=\mathrm{C}_{\mathrm{y}} \mathrm{D}_{\mathrm{y}}$

Total Annual Demand of $x$ and $y$ together (in Rs.) $=T=C_{x} D_{x}$ $+\mathrm{C}_{\mathrm{y}} \mathrm{D}_{\mathrm{y}}$

Joint EOQ (in Rs.), $\mathrm{Q}_{\mathrm{r}}=\sqrt{ }(2 \mathrm{TS} / \mathrm{I})$

EOQ for $\mathrm{x}$ (in Rs. $)=\left(\mathrm{T}_{\mathrm{x}} / \mathrm{T}\right) \mathrm{Q}_{\mathrm{r}}$

EOQ for $\mathrm{y}$ (in Rs.) $=\left(\mathrm{T}_{\mathrm{y}} / \mathrm{T}\right) \mathrm{Q}_{\mathrm{r}}$

EOQ for $\mathrm{x}$ (in units) $=\mathrm{E}_{\mathrm{x}}=\mathrm{EOQ}$ for $\mathrm{x}$ (in Rs.) /Cost (in Rs.) per unit of $\mathrm{x}=\left(\mathrm{T}_{\mathrm{x}} \mathrm{Q}_{\mathrm{r}}\right) /\left(\mathrm{TC}_{\mathrm{x}}\right)$

EOQ for $\mathrm{y}$ (in units) $=\mathrm{E}_{\mathrm{y}}=\mathrm{EOQ}$ for $\mathrm{y}$ (in Rs.) $/$ Cost (in Rs.) per unit of $\mathrm{y}=\left(\mathrm{T}_{\mathrm{y}} \mathrm{Q}_{\mathrm{r}}\right) /\left(\mathrm{TC}_{\mathrm{y}}\right)$

Based on the above analysis, three applicable inventory replenishment policies have been considered. Out of these three, one (CP-3) is based on classical inventory models and two (PP-1 and PP-2) have been proposed in our research. The policies are as given below.

Classical Policy-3 (CP-3): Joint Replenishment based on cycle time

CP-3 is a periodic review policy.

Number of orders per year $=\mathrm{T} / \mathrm{Q}_{\mathrm{r}}$

Cycle time $($ in days $)=\mathrm{t}=365 /\left(\mathrm{T} / \mathrm{Q}_{\mathrm{r}}\right)=365 \mathrm{Q}_{\mathrm{r}} / \mathrm{T}$

With the knowledge of EOQs for $\mathrm{x}$ and $\mathrm{y}$ and common cycle time for $\mathrm{x}$ and $\mathrm{y}$, joint replenishment is considered. In every $\mathrm{t}$ days, lots of $\mathrm{E}_{\mathrm{x}}$ units for $\mathrm{x}$ and $\mathrm{E}_{\mathrm{y}}$ units for $\mathrm{y}$ are received.

Proposed Policy-1 (PP-1): Joint replenishment based on lead time and safety stock

Joint replenishment, considering lead time of $\mathrm{L}$ days and a desired order service level (OSL)
As calculated earlier for CP-2,

ROP for $\mathrm{x}=$ Demand during lead time for $\mathrm{x}+$ Safety Stock for $\mathrm{x}=\mathrm{Ld}_{\mathrm{x}}+\mathrm{z}_{0}\left(\mathrm{~s}_{\mathrm{x}} \mathrm{L}^{1 / 2}\right)$

ROP for $\mathrm{y}=$ Demand during lead time for $\mathrm{y}+$ Safety Stock for $\mathrm{y}=\mathrm{Ld}_{\mathrm{y}}+\mathrm{z}_{0}\left(\mathrm{~s}_{\mathrm{y}} \mathrm{L}^{1 / 2}\right)$

Whenever either inventory of $\mathrm{x}$ reaches to its ROP or inventory of y reaches to its ROP, an order is placed for both $\mathrm{x}$ and $\mathrm{y}$ equaling their respective EOQs for joint replenishment as calculated in this section of 3.1.2, i.e., for $E_{x}$ units of $\mathrm{x}$ and $\mathrm{E}_{\mathrm{y}}$ units of $\mathrm{y}$.

Proposed Policy-2 (PP-2): Joint replenishment based on lead time, safety stock and a proposed lot-sizing rule

A joint replenishment policy has been proposed for the items associated. Considering an association rule, $x=>y$, the steps involved in the proposed inventory replenishment policy are:

(i) Calculation of EOQ for Joint Replenishment of $\mathrm{x}$ and $\mathrm{y}$ (as calculated in this section of 3.1.2)

(ii) Calculation of Safety Stock and ROP for both the items (as explained in CP-2)

(iii) Whenever inventory reaches ROP of either item, place an order.

(iv) Amount of order quantities to be placed for $\mathrm{x}$ and $\mathrm{y}$ is calculated as given below.

Illustration with an example:

From joint replenishment policy, EOQs for $\mathrm{x}$ and $\mathrm{y}$ have been calculated as $\mathrm{E}_{\mathrm{x}}$ and $\mathrm{E}_{\mathrm{y}}$ respectively.

As explained in CP-2, ROPs for $\mathrm{x}$ and $\mathrm{y}$ are $\mathrm{r}_{\mathrm{x}}$ and $\mathrm{r}_{\mathrm{y}}$ respectively.

Three possible situations are:

(i) Inventory level of $x$ has reached to $r_{x}$

However, inventory of $y$ in stock $=I_{y}\left(I_{y}>=r_{y}\right)$,

Then an order for $E_{x}$ units of $x$ and $\left(E_{y}-I_{y}+r_{y}\right)$ units of $y$ should be placed.

(ii) Inventory level of $y$ has reached to $r_{y}$.

However, inventory of $x$ in stock $=I_{x}\left(I_{x}>=r_{x}\right)$,

Then an order for $E_{y}$ units of $y$ and $\left(E_{x}-I_{x}+r_{x}\right)$ units of $x$ should be placed.

(iii) Inventory level of $\mathrm{x}$ has reached $\mathrm{r}_{\mathrm{x}}$ and inventory level of $y$ has reached $r_{y}$ simultaneously.

An order for $E_{x}$ units of $\mathrm{x}$ and $\mathrm{E}_{\mathrm{y}}$ units of $\mathrm{y}$ should be placed.

So far we have discussed two policies (CP-1 and CP-2) based on individual replenishment and three policies (CP-3, PP-1 and PP-2) based on joint replenishment. Based on the costeffectiveness, all the policies can be compared and the best one can be suggested for implementation.

\section{METHODOLOGY}

Knowledge of purchase dependency in demand of the items is captured by mining association rules from past transaction data. Association rules are used for future decision making. We have used the knowledge of purchase dependency in demand as depicted by the association rules in inventory replenishment policy. For the purpose of present research, two sets of data have been synthesized using random numbers - 
one set represents past sale transaction data and another represents demand data for future, both in binary form, given by 'presence' or 'absence' of item in the transactions. The process of generation of these two data sets has been designed in such a way that both sets yield the same intended association rule with same values for support, confidence and lift. This ensures two data sets representing same demand purchase dependency in the purchase pattern of the customers with same intensity. It is to be noted that in real situations, we don't need to generate past sale transaction data as we will have real past transaction data available with us. Association rules can be mined from the past transaction data. Hence, in real situations, we need to generate only one set of data for future demand data and it must be ensured that this data yields the same intended association rule as mined from the past transaction data with same values for support, confidence and lift. To compare the performances of various inventory replenishment policies, generated future demand data is used where simulation of various policies can be done. A procedure has been developed to convert random numbers into past transaction or future demand data so that an association rule is observed in both the data sets with same values of support, confidence and lift.

On the predicted demand data for future, various inventory replenishment policies have been simulated and results have been analyzed. Based on the relevant inventory costs, performance analysis has been made.

\section{RESULTS AND CONCLUSION}

Based on five replenishment policies discussed above, the comparative summary of the results are given in table $-\mathrm{I}$.

Table 1. Comparison of Inventory Policies for Kismis and Basmati

\begin{tabular}{|l|c|c|c|c|c|}
\hline & P-1 & P-2 & P-3 & P-4 & P-5 \\
\hline $\begin{array}{l}\text { Ordering } \\
\text { Cost } \\
\text { (Rs.): Co }\end{array}$ & 107.2 & 103.5 & 75.0 & 77.8 & 77.8 \\
\hline $\begin{array}{l}\text { Holding } \\
\text { Cost } \\
\text { (Rs.): Ch }\end{array}$ & 185.8 & 123.5 & 94.5 & 100.4 & 92.8 \\
\hline $\begin{array}{l}\text { Lost Sale } \\
\text { Cost } \\
\text { (Rs.): Cs }\end{array}$ & 1635.4 & 759.0 & 742.9 & 669.5 & 653.9 \\
\hline $\begin{array}{l}\text { Total } \\
\text { Cost (Rs.) } \\
= \\
\text { Co+Ch+ } \\
\text { Cs }\end{array}$ & 1928.4 & 986.0 & 912.4 & 847.7 & 824.5 \\
\hline
\end{tabular}

The paper gives a methodology to compare different applicable inventory replenishment policies in the context of multi-item inventory with large number of items and having interdependent demand amongst the items represented by the association rules. Hence, the methodology is useful in selecting the best replenishment policy out of all the applicable policies which can be implemented. The best replenishment policy can be obtained by simulating various policies on generated future demand data with the same purchase dependency in demand as observed in the past data. It is observed that for the example discussed in our experimentation, the PP-2 (Joint replenishment based on lead time, safety stock and a proposed lot-sizing rule), one of the two proposed policies, results in minimum annual inventory cost and hence, PP-2 can be used in its replenishment. The suggested methodology in our research will be useful for replenishment of inventory with demand purchase dependency and large number of items where the past sale transaction data in available for mining association rules.

Some of the limitations in the present research include the fact that to generate future demand data, association rule is used which is mined from past sale transaction data. However, past sale transaction data is actually not necessarily the same as past demand data. This is because of the possibility of some demands not being materialized into sale due to stock out situation of the item or the associated item having an impact on its demand. In reality, we mine association rule from past sale transaction data (which is generally found available in the system) and not from past demand data (which is generally never collected), assuming that in the long run the sale data reflects the pattern of purchase. In reality, the transaction of an item happens with any possible number of units. However, in the generation of transaction or demand data in the present research, we have restricted it only to 'one unit' of sale. The methodology can be devised to generate transaction or demand data with various possible units of an item. Scope of quantitative association rule may also be explored for such cases.

In the example discussed in this paper, we have considered a 'one-to-one' type of purchase dependency given by association rule, in the form of ' $x=>y$ '. Experimentation can also be done with purchase dependency amongst number of items represented by association rules of 'one-to-many', 'many-to-one' or 'many-to-many' type. Moreover, a number of interdependencies playing together provide further scope for research.

\section{REFERENCES}

[1] Silver, E. A., Pyke, D. F., and Peterson, R. 1998. Inventory Management and Production Planning and Scheduling, 3rd ed., New York: Wiley, ISBN 0-47111947-4.

[2] [2] Narasimhan, S.L., McLeavey, D.W. \& Billington, P.J. 2002. Production Planning and Inventory control, Prentice Hall of India.

[3] Brown, R.G. 1967. Decision Rules for Inventory Management, New York: Holt, Reinhart and Winston

[4] Goyal 1974. Optimal Order Policy for a Multi-item Single Supplier System, Operational Research Quarterly, Vol. 25, 293-298

[5] Silver, E.A. 1976. A Simple Method of Determining Order Quantities for Joint Replenishment for Deterministic Demand, Management Science, .22 (12), 1351-1361.

[6] Gallego, G., Queyranne, M. \& Simchi-Levi, D. 1996. Single Resource Multi-Item Inventory Systems. Operations Research, 44 (4), 580-595. 
[7] Teo, C.P., Ou, J. \& Tan, K.C. 1998. Multi-Item Inventory Staggering Problems: Heuristics and Bounds. Proceedings of the Ninth Annual Ace-Siam Symposium on Discrete Algorithms, By Association for Computing Machiner. San Francisco, California, United States.

[8] Carlos, B.R.C. \& Armando, J.E.d.l.M.F. 1997. Evaluation of a (R,s,Q,c) multi-item inventory replenishment policy through simulation. Proceedings of the 1997 winter simulation conference, Atlanta, Georgia, USA, 825-833

[9] Peter, L.J. 2004. A multi-echelon multiiitem inventory model for service parts management with generalized service level constraints. OR\&IE Seminar, School of ORIE, Cornell University.

[10] Aviv,Y. \& Federgruen, A. 2001. Capacitated multi-item inventory systems with random and seasonally fluctuating demands: Implications for postponement strategies. Management Science, 47(4), 512-531.

[11] Babak Ghalebsaz-Jeddi, Bruce C. Shultes, and Rasoul Haji 2004. A multi-product continuous review inventory system with stochastic demand, backorders, and a budget constraint, European Journal of Operational Research $158(2), 456-469$.

[12] Liu \& Yuan 2000. Theory and Methodology: Coordinated replenishments in inventory systems with correlated Demands. European Journal of Operational Research 123 (3), 490-503.

[13] Bhattacharya, D.K. 2005. Production, Manufacturing and Logistics on Multi-Item Inventory, European Journal of Operational Research 162 (3) 786-791.

[14] Srikant \& Agrawal 1995. Mining Generalized Association Rules, Proceedings of the $21^{\text {st }}$ International Conference on Very Large Databases, Zurich, Switzerland, 407-419.

[15] Wong, W., Fu, A.W., and Wang, K. 2005. Data Mining for Inventory Item Selection with Cross-Selling Considerations. Data Mining and Knowledge Discovery, $11(1), 81-112$.

[16] Bala, P.K. 2008. Retail Inventory Management with Purchase Dependencies, Engineering Letters, vol. 16 (4), 545-549.

[17] Bala, P.K. 2009. Data Mining for Retail Inventory Managements, Advances in Electrical Engineering and Computational Science, LNEE Series (Ao-Gelman Eds.), Springer, Vol. 39, 587-598.

[18] Bala, P.K, Sural, S., Banerjee, R.N.. 2010. Association Rule for Purchase Dependence in Multi-Item Inventory, Production Planning \& Control, Vol. 21 (3), 274-285. 